\title{
Festival Elements: A Source of Inspiration for Contemporary Fashionable Products
}

\author{
Solomon Marfo Ayesu' ${ }^{*}$, Mercy Ampofowah Osei ${ }^{2}$, Cynthia Akua Chichi ${ }^{3}$, Richard Acquaye \\ ${ }^{1}$ Department of Fashion Design and Textiles Studies, Kumasi Technical University, Kumasi, Ashanti Region, Ghana \\ ${ }^{2}$ School of Fashion and Design (Blue Crest College), Accra, Ghana \\ ${ }^{3}$ Department of Industrial Art, KNUST-Kumasi, Ghana \\ ${ }^{4}$ Department of Textiles Design and Technology-Takoradi Technical University, Takoradi, Ghana \\ Email: *solomaxxy@rocketmail.com, *solomon.amarfo@kstu.edu.gh, ampofowah63@gmail.com, cachichi.cass@knust.edu.gh, \\ richard.acquaye@ttu.edu.gh,nrencho@yahoo.com
}

How to cite this paper: Ayesu, S.M., Osei, M.A., Chichi, C.A. and Acquaye, R. (2020) Festival Elements: A Source of Inspiration for Contemporary Fashionable Products. Journal of Textile Science and Technology, 6, 200-217.

https://doi.org/10.4236/jtst.2020.64017

Received: April 12, 2020

Accepted: November 22, 2020

Published: November 25, 2020

Copyright $\odot 2020$ by author(s) and Scientific Research Publishing Inc. This work is licensed under the Creative Commons Attribution International License (CC BY 4.0).

http://creativecommons.org/licenses/by/4.0/

\begin{abstract}
Festivals are intrinsic aspects of the culture of a group of people and allow displaying interesting crafts and elements such as fabrics, symbols, folktales, and paraphernalia. The dynamism in the culture is vast but unexplored as inspiration for the creation of products. This created the need to explore the possibility of designing contemporary print and products from these crafts and elements from two festivals (Aboakyir and Gologo) using Adobe Photoshop in the design process. This phenomenon necessitated the consideration of this project which was undertaken by employing the design-based practice coupled with observation as an instrument. Elements related to the festivals were identified and using the design process, print designs were developed and further simulated on different products. This practice seeks to promote the cultural heritage of the people to a wider populace and the world at large. It is recommended that the Traditional Council should have a museum or gallery for keeping the artworks used in their festivals for archival purposes.
\end{abstract}

\section{Keywords}

Festivals, Cultural Elements, Adobe Photoshop, Fashionable Products, Paraphernalia

\section{Introduction}

From the incredible patterns created with the traditional loom, the stamping of symbols on the cotton fabric to the rhythm on the "fontomfrom" drum, Ghana like other countries in Africa is blessed with cultures that have philosophical underpinnings and history that are exceptional and embedded in the livelihood 
of the individuals. These cultures are intrinsic and have transcended generations. In portraying the rich material culture, Ghanaians use fabrics that are either woven or printed with symbols that mostly communicate values, norms, and information to the societies. The symbols that are vigorously used are from the Ashanti tribe in Ghana (Adinkra) and proverbial sayings and are translated into fabric designs that are printed and fashioned into products to meet the needs of the consumers. This is due to the dominance of the Ashanti tribe in the nation but other cultures have interesting, historical elements that can be explored to create diversity, inclusion, and appeal to a wider populace and the world at large.

Ewe proverbs were used as inspiration as seen in Figure 1 with the justification of the extensive use of Adinkra symbols by different designers to create outstanding print designs to portray the rich culture of the Volta Region of Ghana [1]. Prior to the innovation of Adobe Photoshop, designers had to resort to manually identifying and translating these proverbial symbols and ideas into workable images, work on colour separation, screen development, and printing or the making of the product. The introduction of Adobe Photoshop has enhanced the design and production of items through digital manipulation, replication, and simulation of inspirational elements to achieve precision and accuracy [2] in the work of Beazley and Bond. They further opined that the choice of Adobe Photoshop made it easier in manipulating the symbols for the designs even though the creative process for cutting patterns on wood blocks for printing was essentially difficult and time-consuming [2].

As an alternative to the overused Ashanti symbols, other cultures that had interesting festivals like the Odwira festival from the Akuapem, regarded as an avenue for unity, strength, socio-cultural and economic development for the indigenes, had been studied and utilized [3]. The researcher asserted that the Odwira festival was steeped with crafts and cultural elements which had philosophical underpinning which led in the development of print-designs which were further used for the production of regalia (umbrella and palanquin) as shown in

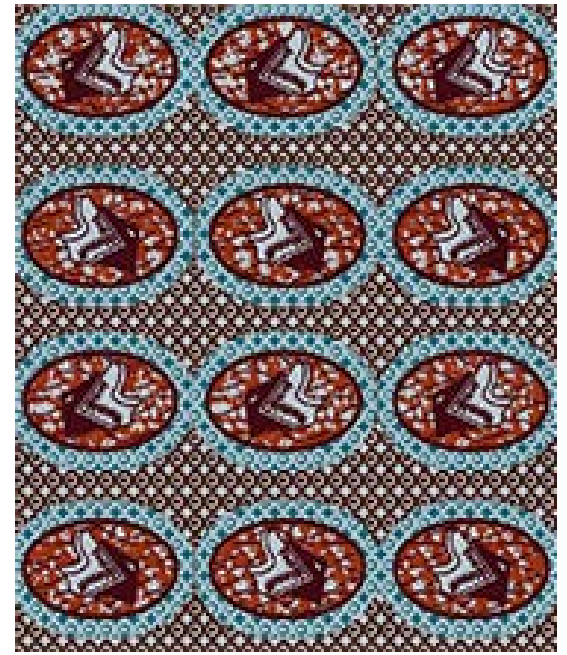

Figure 1. Print designs inspired by Ewe proverbs (Source: Vigbedor, et al., 2016). 
Figure 2. This project adopted the use of Adobe Photoshop and hand-screen printing in creating designs using eight totems and five divisional symbols. The findings revealed that designing an umbrella and palanquin using totems and symbols was representational and a means of portraying their identity. Also, the choice of velvet fabric for the production was due to its smoothness, durability, and description as a royal fabric [3].

To promote the aesthetics and philosophical values of the linguist staff symbols in the Asante culture, [4] developed textile designs (Figure 3) with these elements for the commercial market through the use of special texturing effects and motifs from the linguist staff. Safa-Ankama, inspired by the structure of the stripes in the Daboya fugu which is a traditionally fashioned garment produced by the people in Northern Ghana, created designs using CorelDraw software and hand screen printing for "Jdo $d w a$ " (love chair) ideal for leisure and relaxation as shown in Figure 4 [5]. This equally influenced the conceptualization and production of a seat from the traditional symbol from Ghana, (Figure 5) which was embedded with the traditional symbolism [6].

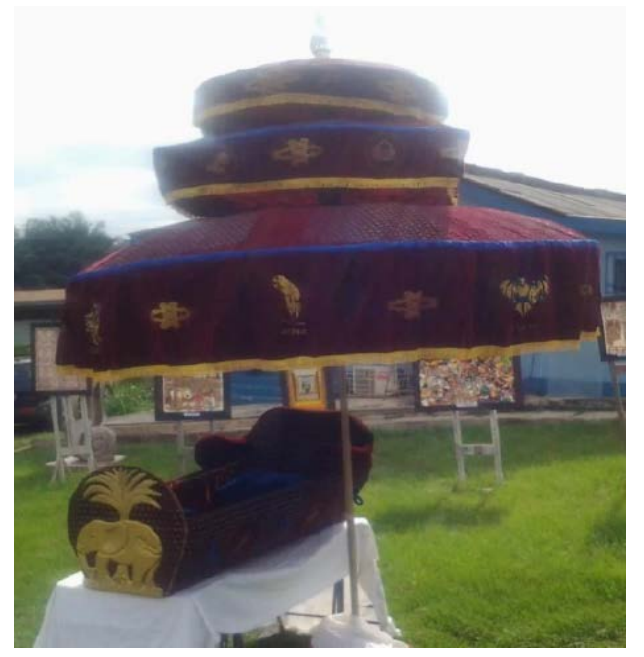

Figure 2. Textile Regalia inspired by Akuapem state symbols (Source: Ayesu, 2016).

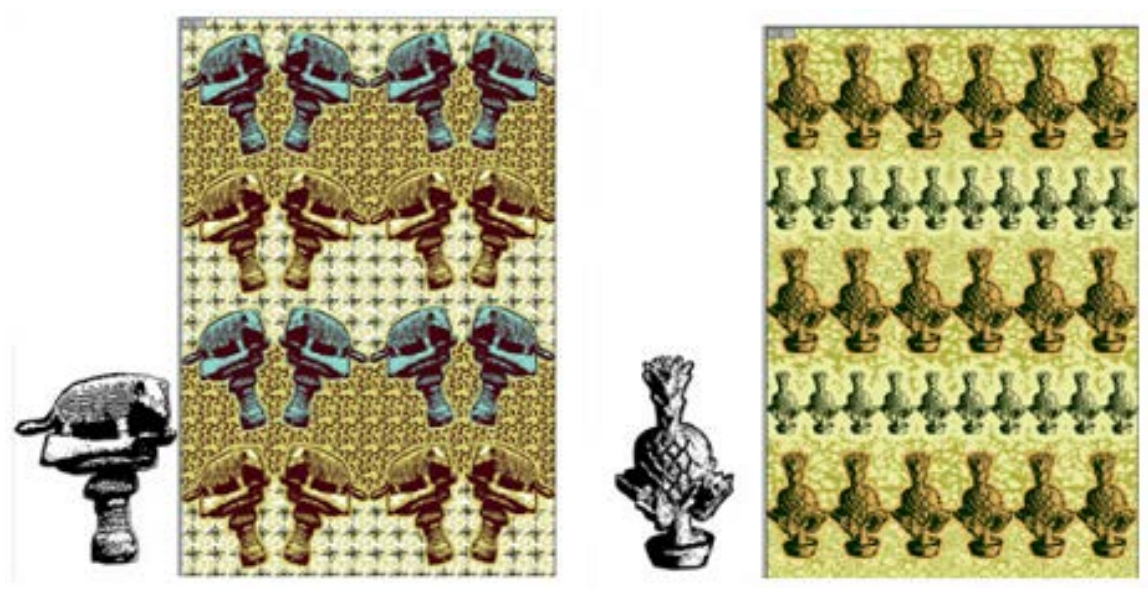

Figure 3. Designs inspired by linguist staff (Source: Asare, et al., 2016). 


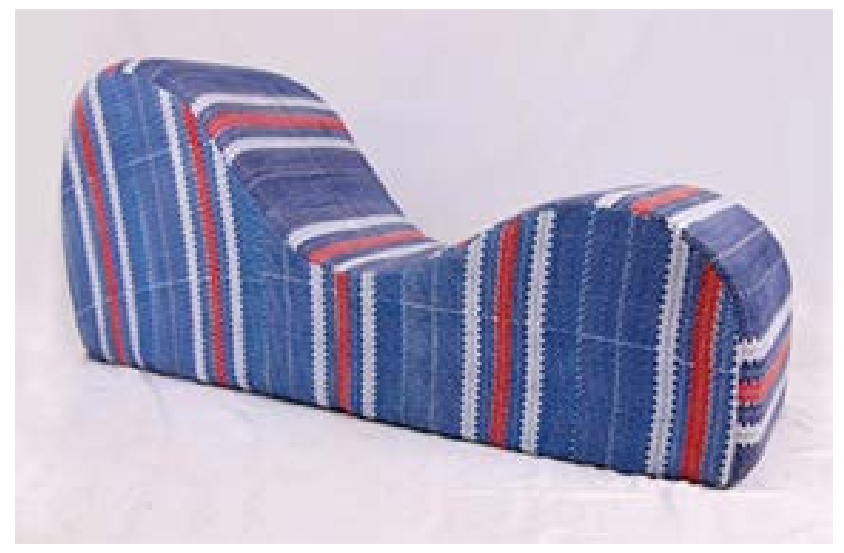

Figure 4. A print design for Jdo dwa inspired by Daboya fugu stripes (Source: Safo Ankama, 2019).

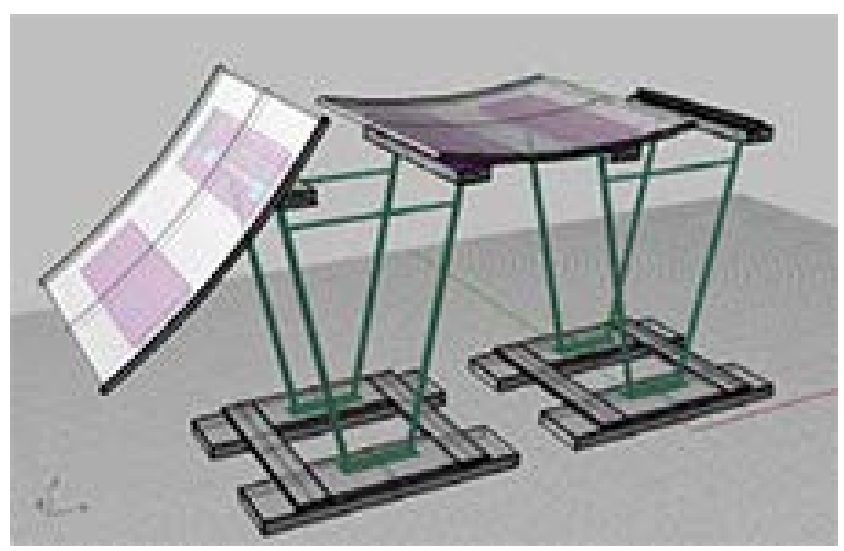

Figure 5. Seat inspired by a traditional symbol from Ghana (Source: Clement, 2011).

Cultural elements have continued to be an important source of inspiration for most designers, which seeks to promote the rich heritage of the indigenes. The choice of Adobe Photoshop coupled with alternative techniques from the research studies, played a critical role in the creative process to ensure the product was embedded with dimensional and aesthetic values. Considering the path of some designers outlined and contemporary trends (interesting colour schemes, minimalism in design patterns, the choice of elements from culture and nature amongst others), Adobe Photoshop, especially Photoshop, has been a "saviour" in the design and simulation process on different fashionable products. To explore the myriad of elements that can be used in creating products, two selected festivals (Aboakyir and Gologo) in Ghana were identified and utilized for this research to bring to bear the possibility of producing interesting but trendy designs that can be applied in fashion products from other cultures other than the Ashantis.

\subsection{Festivals as a Symbolic Element in Culture}

Festivals play a vital role in the cultural heritage of a group of people and is a means of showcasing rich traditional crafts. According to Oduro-Awisi as cited 
in Ayesu (2016), festivals are traditional gatherings that seek to celebrate historic occurrences or ancestors for their protection and guidance. These celebrations employ different tangible (food, fabrics, linguist staff, regalia, and umbrellas amongst others) and intangible elements (proverbs, folklore, folk tales, etc.) that carry symbolic connotations [7].

Festivals are a celebration where the social and symbolic meaning of the events is closely related to a series of overt values that the communities recognized as essential to their ideologies and world view [8]. While dependent upon life-sustaining rituals, festivals often become the social, ritual, and political opportunity of community life in a year [9]. Examples of harvest festivals in Ghana are; Homowo festival of Ga people of Ghana, Asogli yam festival of the people of Ho, Ghana, Adaa-Kuya festival of the people of Bolgatanga, Ghana, Hunting festivals; Aboakyir festival of the Effutus, Masquerade festival of Winneba, Saltpond and Sekondi, Ghana, fishing festivals; commemorative festival; Akwasidae festival of the Asantes, Ghana, dance festival; a festival for the ancestors; Akomase festival of the Effutus, Ghana. Festivals have been one of the elements of culture that has stood the test of time, right from the pre-colonial era, colonial and post-colonial era [10]. In Ghana, traditional festivals are important cultural elements that are identified with many ethnic groups across the country with works of art and actions in songs, dances, sculptures, and costumes bearing rich cultural significance.

\subsection{Costumes Used During Festivals}

Every ethnic group in the country, Ghana, has its customized costumes which include; garments, accessories, and hairstyles with its origin in the past [11]. Costumes are seen as different from everyday clothing and are "used as a form of symbolic expression of oneself as well as a communicative tool that interprets its sociological effects at any given time" [12]. This view is shared by [11] [13] as a symbol that reflects the communal spirit of the society other than the personality of the wearer and that "most costumes are produced traditionally in connection with religious rituals, marriages, social groups as well as to show social status". These costumes, shown in Figure 6 and Figure 7 are costumes commonly worn to festivals in Ghana.

An ethnic costume is a strong statement of individual circumstances because it is unique and has a cultural background. Each historical region has its own specific variety of costume [14]. Festivals are not mere occasions of enjoyment and merry-making, but they are also platforms for the social, religious, and economic development of the society in which they are celebrated [15]. Such catchy and remarkable costumes of significant importance are those worn during the Aboakyir festival of the Effutus in the Central Region and Gologo festival of the Talensi people in the Upper West Region of Ghana.

\subsection{Aboakyir Festival}

Aboakyir is one of such traditional festivals celebrated annually by a Guan ethnic 


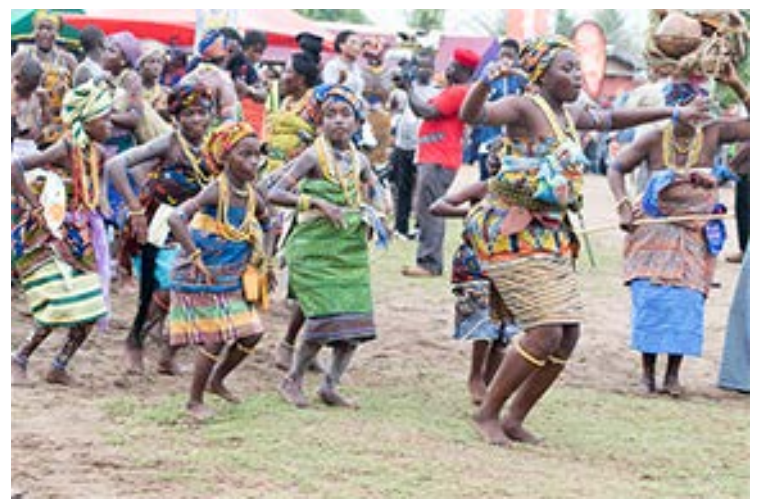

(a)

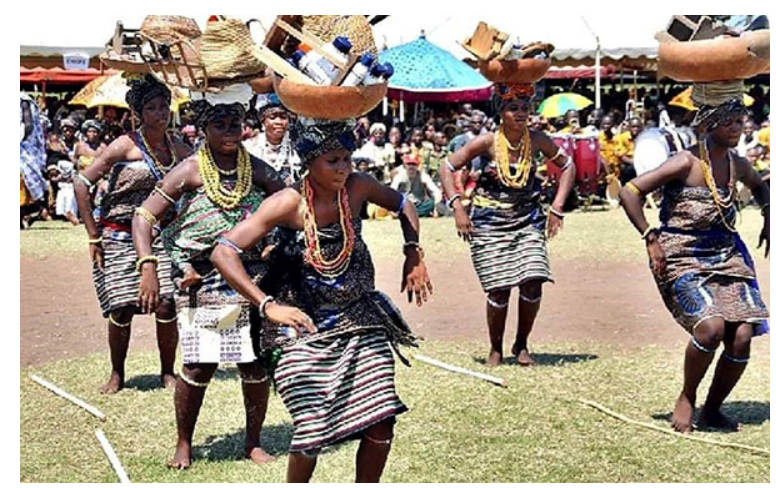

(b)

Figure 6. $(\mathrm{a}, \mathrm{b})$ Costumes worn to festivals (Source: https://en.wikipedia.org/wiki/Agbadza).

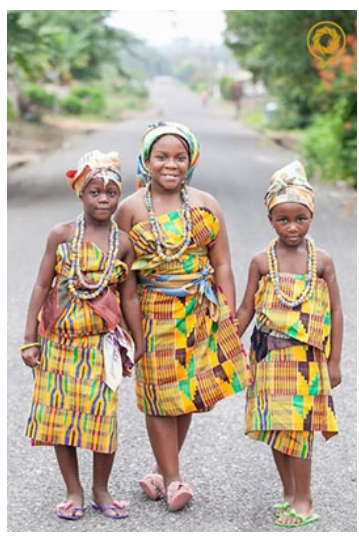

(a)

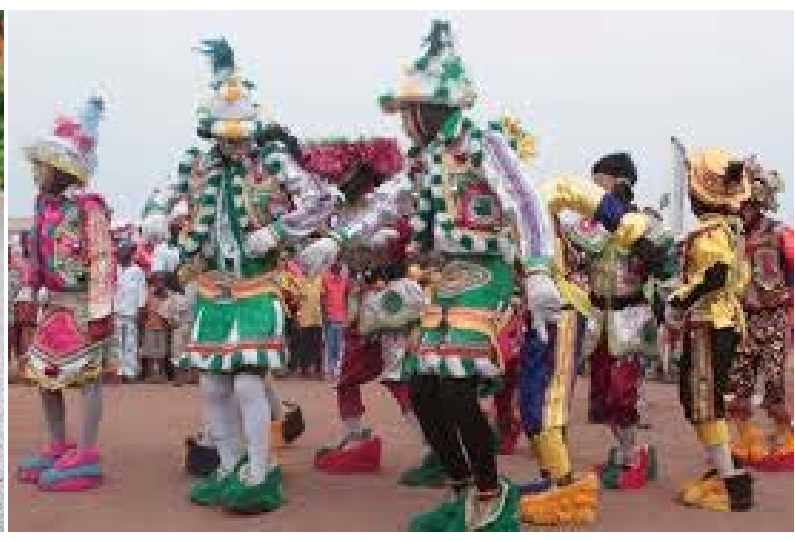

(b)

Figure 7. (a, b) Costumes worn to festivals (Source:

https://kwekudee-tripdownmemorylane.blogspot.com).

group in the Central Region called Simpa or Effutu. The Effutu people with an emblem (Figure 8) celebrates the festival at their traditional capital called Winneba every first week of May. The Simpa people are famous for their traditional Deer Festival called Simpa Aboakyir. It is celebrated to honour their ancestral god called "Apasekum" who led them during their migration from Western Sudan to their present abode. Historically, the people pleaded with "Apasekum" 


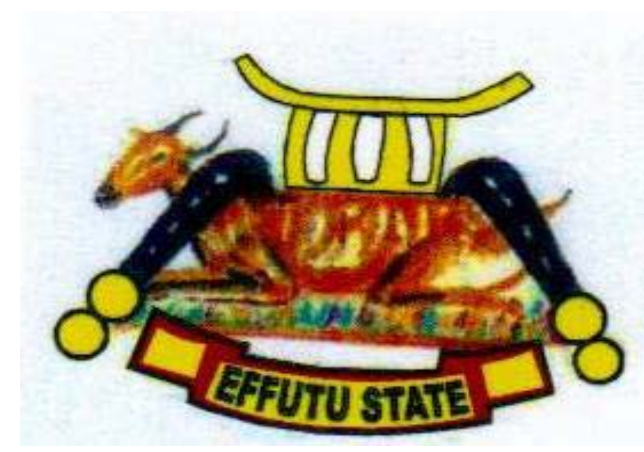

Figure 8. Emblem of the Effutu state (Source: Palace of Oma Odefe).

through the fetish linguist god "Otu" to substitute the annual human sacrifice with something else and the god heeded to their plea and substituted with a live Leopard. Upon persistent plea with "Apasekum", the deity selected a live Deer to replace the live Leopard largely due to its blood and skin similarities [10]. Most of the rituals are performed by chiefs, fetish priests and priestess, and the two Asafo Companies; Tuafo, No. 1 and Dentsifo, No. 2 (Figure 9), and indigenous groups. The event is always characterized by the display of hairstyles (Figure 10) and artefacts finished in rich flamboyant colours that create a high sense of aesthetics especially at the durbar grounds on Saturday. The energetic and enthusiastic characteristics associated with the involvement of these artefacts in the festivals play functional, economic, and aesthetic roles that are indispensable to the culture of the people [10].

\subsection{Gologo Festival of the People of Tongo}

The Talensi people of Tenzug in the Upper East Region celebrates one of the rarest festivals in the country of Ghana. It is celebrated to reinforce the community belief in the "Nnoo" shrine or "Golib" god which regulates Talensi agricultural life. It is a pre-harvest festival celebrated in March and April at the end of the dry season before the sowing of the early millet. Libation is poured at the Teng-Zug shrine to thank the gods for a successful occasion [16]. The prominent features of the costume include towels of different sizes and colours, knives of different sizes, and the wearing of triangularly shaped aprons. It is a tradition that people around the festive area should not put on clothes to cover the upper part of their bodies so the women resort to using the bigger towels which can be wrapped around their bodies as indicated in Figure 11 and Figure 12.

Zorl is made from hairs from a horse either white or black and is used for war dance which signifies the strength and willingness to face challenges. The "zorP" (Figure 13) is also used by the fetish priest as a symbol of his powers.

The "Nansa" (Figure 14) is a metallic dangle worn around the ankle and is used in the dance as a musical instrument. It is these sounds that the performers dance to amid singing. "Gbared" (Figure 15) is a leather belt worn by the war dancers in the festival to beat the people who do not follow tradition and culture but are on the festival grounds to show disrespect [17]. 


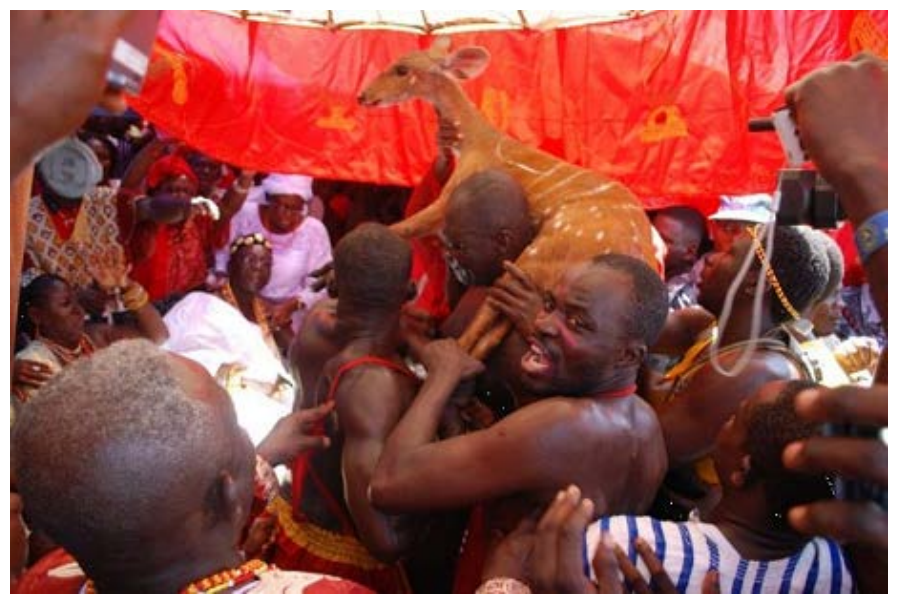

Figure 9. The Dentsefo No. 2 with a catch at the durbar ground (Source: Impraim-Swanzy, 2015).

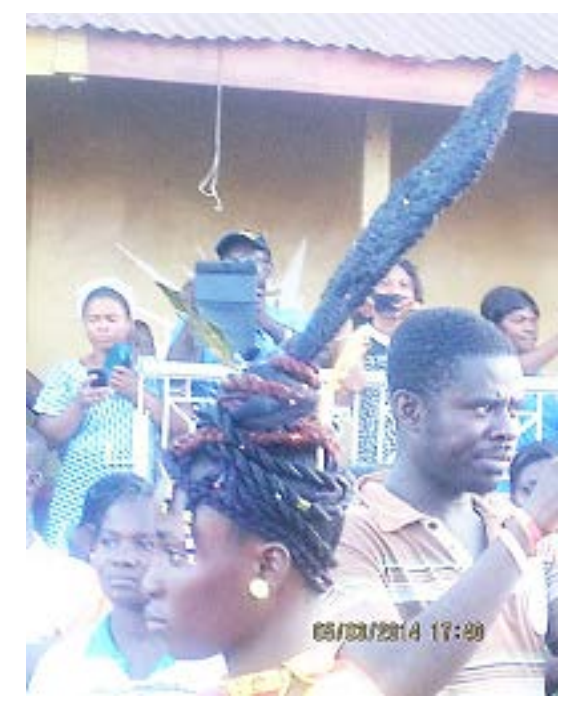

Figure 10. Hairdo seen during the Aboakyir festival (Source: Impraim-Swanzy, 2015).

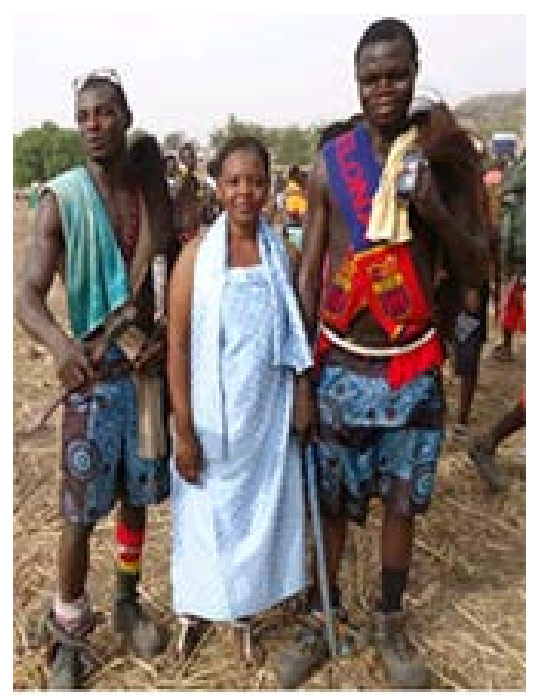

Figure 11. Female spectator and male preformance (Source: Adjei and Osei-Sarfo, 2016). 


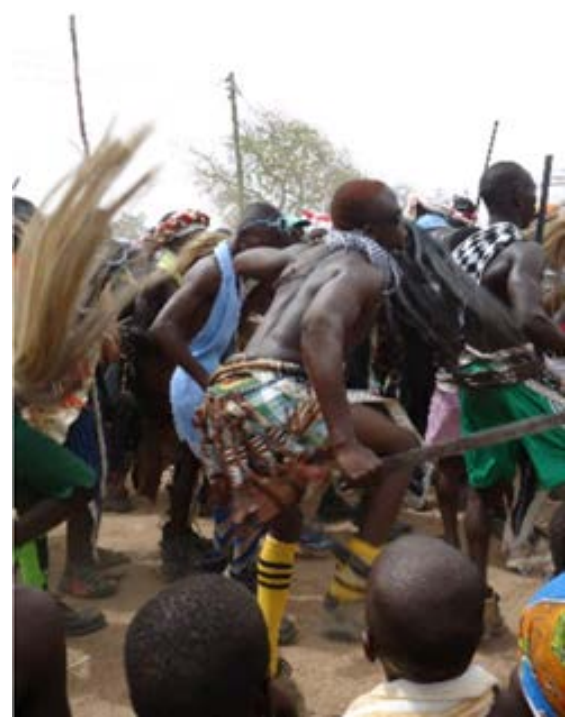

Figure 12. Male Preformance at a dance (Source: Adjei and Osei-Sarfo, 2016).

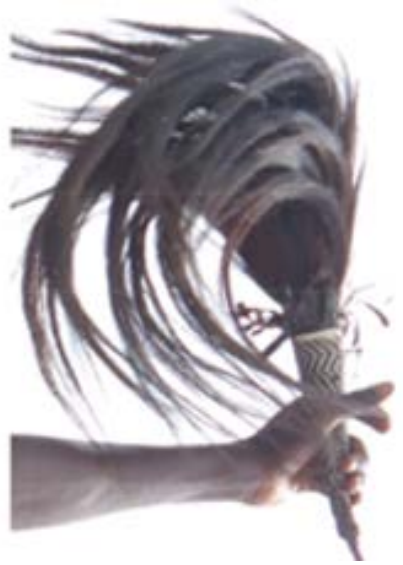

Figure 13. Zorl (Source: Adjei and Osei-Sarfo, 2016).

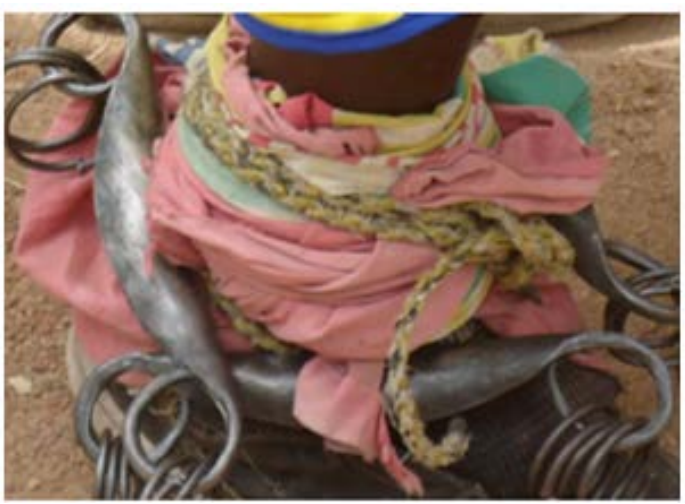

Figure 14. Nansa (Source: Adjei and Osei-Sarfo, 2016).

Knives, bow, and arrows (Figure 16), horns, and other items which could be used for fighting are also visible during the dance. The most prominent of these is the "golob sul" which is a long knife willed by dancers. The images from the 


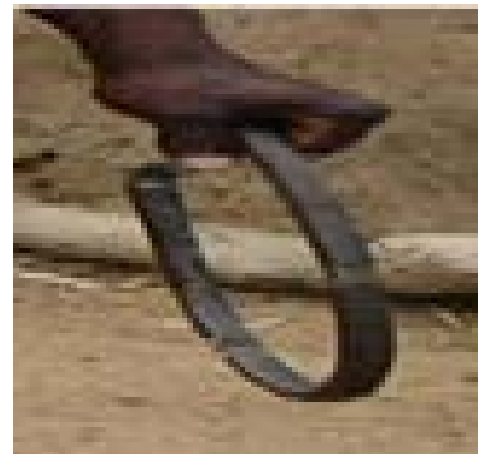

Figure 15. Gbared (Source: Adjei and Osei-Sarfo, 2016).

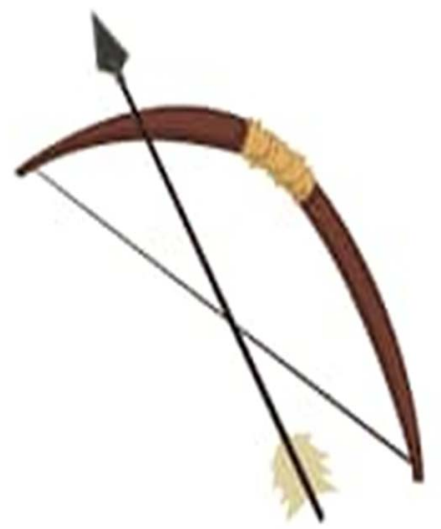

Figure 16. Bow and Arrow (Source: Adjei and Osei-Sarfo, 2016).

Aboakyir and Gologo festivals which include; the deer, the Effutu emblem, congregants celebrating the festivals, hunters, bows, and arrows, costumes, dance, were some of the cultural elements selected and with the aid of Adobe photoshop explored to create and simulate designs that could serve as paraphernalia for tourists and the populace.

\section{Methodology}

The study employed studio-based research practice which is a flexible methodology aimed to improve educational practices through iterative analysis, design, development, and implementation. It utilized the Aesthetico-action research cycle which includes observation, reflection, planning, and the creation of products. In the research undertaken, observations were made during the Aboakyir and Gologo festivals to identify elements that could be used in executing the work, these were reflected on with concepts that were achieved with the aid of mood board. This led to the planning and creation, reflection, and prototyping of the product which in this scenario were simulated to see the outcome. To help achieve this systematically, a framework (Figure 17) was constructed which aided in the design process. This five-stage process is comprised of; identification of the need, research inspiration, research direction, creative process, and production of prototypes. 


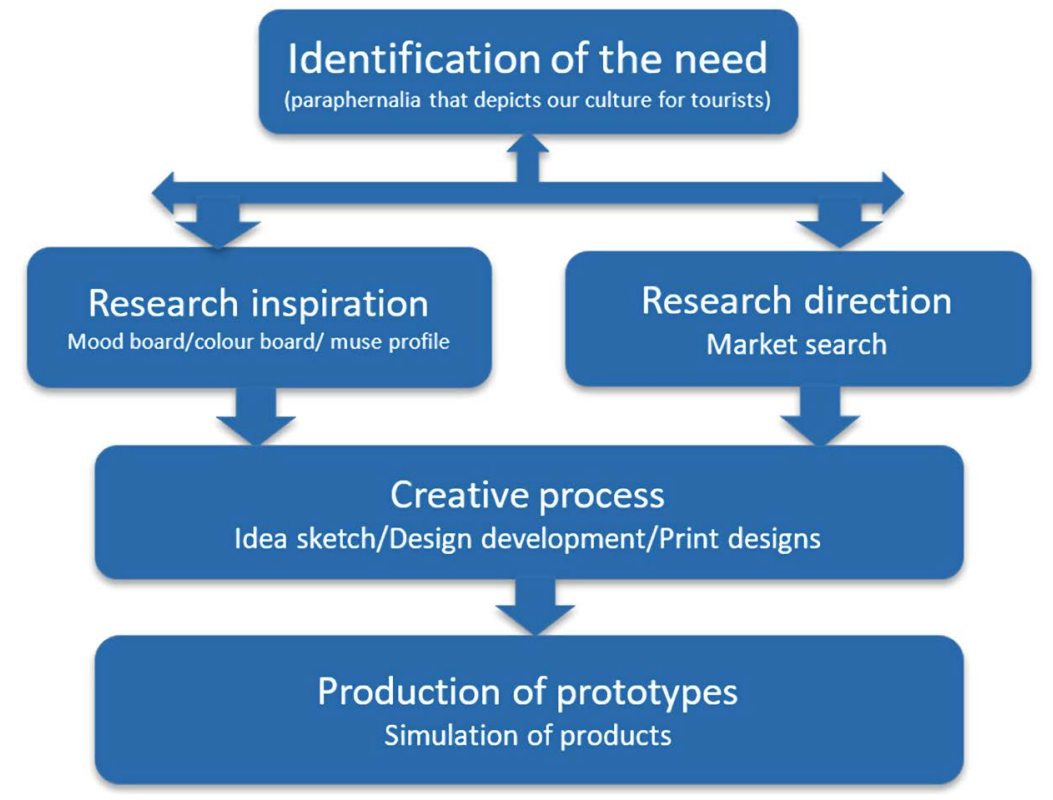

Figure 17. Conceptual framework (Source: Authors Construction, 2019).

\subsection{Identification of the Need}

Enhancing one's appearance with fashionable items in contemporary times has influence designers and manufacturers to produce interesting artefacts. Thus, the researchers observed and identified that consumers continue to improve their surroundings using products with culture inspired designs for clothing, automobile interior, footwear, bags, the interior of buildings amongst others, a situation that is dependent on the dynamism of fashion coupled with the preference of consumers. The researchers identified that there were no artefacts or products with inspiration from the Aboakyir or Gologo festivals that could be used for such purposes and once the activities were over, there were no memorable paraphernalia to commemorate this amazing occasion. For the tourist, there only memory was images and mental pictures of the events which necessitated the need for this research to help create memories that could be relived for a long time in the form of products.

\subsection{Research Inspiration}

Inspiration was drawn from items and symbols used during the celebration of the festivals (Aboakyir and Gologo) which was transformed with other elements into the development of a mood board (Figure 18) with colour scheme that placed a role in the creative process. Some images from the Aboakyir festival which include; the deer, the Effutu emblem, and congregants celebrating the festival, were selected and used to create a mood board (Figure 18) from which ideas were couched.

Employing the observation method in the design practice, yellow, orange, blue, green, red, brown, black, and white colours were identified from the $A b$ oakyir festival and red, blue, olive green, and black from the Gologo festival. 

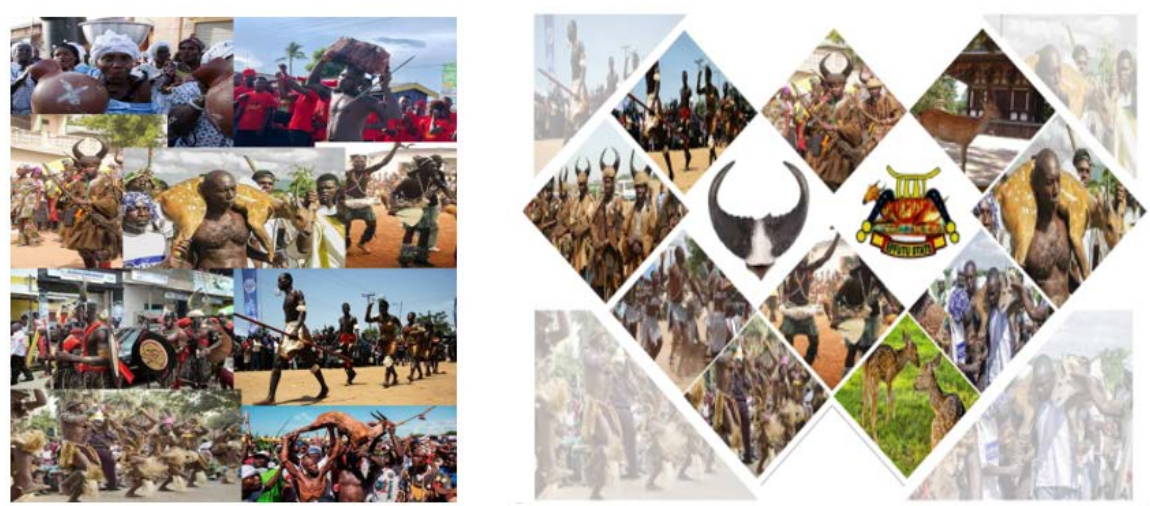

Figure 18. Mood board (Source: Studio Practice, 2019).

\subsection{Research Direction}

This section highlights the target costumers for the print designs coupled with the products.

\section{Demographics,}

\begin{tabular}{ll}
\hline Age: $30-60$ & Gender: Unisex, \\
Habitation: foreigners & Family Life Cycle: Married straight \\
Size: any size. &
\end{tabular}

\section{Psychographics,}

\begin{tabular}{ll}
\hline Personality: practical, and organized & Attitude: lively \\
Interests: familiarity and knowledge-seeking & Purpose - Shopping, \\
Fashion Preferences: crafts, artefact & Lifestyle: traveling, love for the arts.
\end{tabular}

It is estimated that Ghana will annually rake in US\$8.3 billion $(\$ 8,300,000,000)$ from the tourism sector per year by the year 2027. This is based on the back of an estimated 4.3 million international tourist arrivals. The introduction of the year of return was expected to bring foreigners in search of their roots and 2019, it brought celebrities like Steve Harvey, Samuel L. Jackson, Idris Elba, and much more.

\subsection{Creative Process}

As mentioned earlier on, Adobe Photoshop, widely used by contemporary designers was employed in the creative process to manipulate the elements. Adobe Photoshop played a critical role in design simulation processes. Outlined below are the selected elements (Figures 19(a)-(f)) from the two festivals observed in the study.

\subsection{Design}

Festivals are intrinsic aspects of the culture of a group of people and allow 


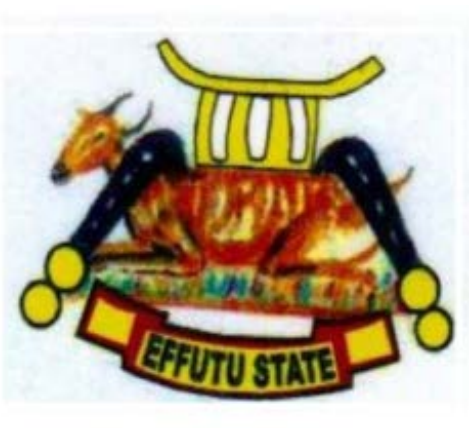

(a)

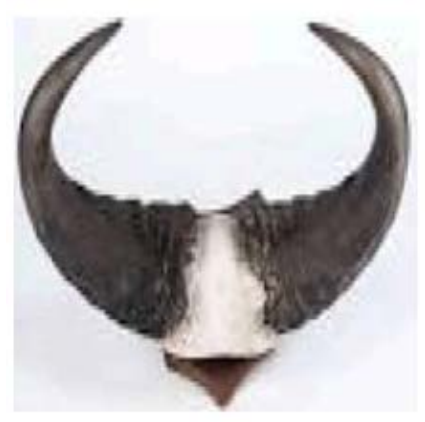

(d)

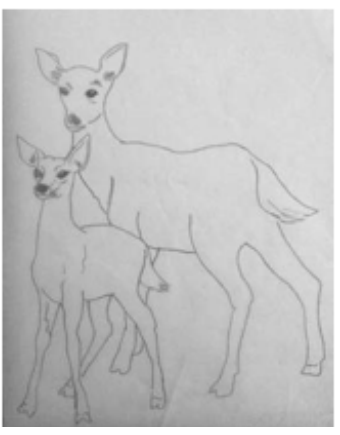

(b)

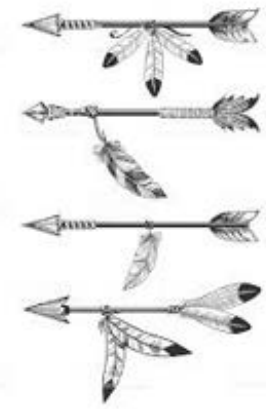

(c)

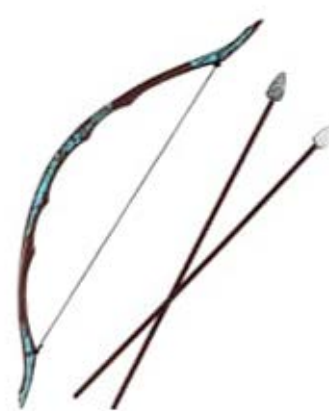

(e)

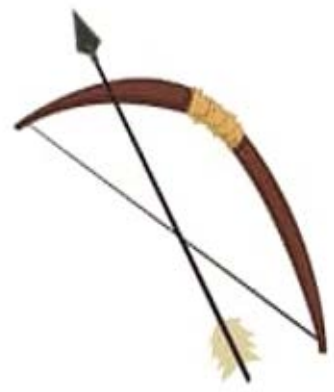

(f)

Figure 19. (a-f): Selected festival elements (Source: Studio Practice, 2019).

displaying interesting crafts and elements such as fabrics, symbols, folktales, and paraphernalia.

The dynamism in the culture is vast but unexplored as inspiration for the creation of products. This created the need to explore the possibility of designing contemporary print and products from these crafts and elements from two festivals (Aboakyir and Gologo) using Adobe Photoshop in the design process.

Subsequently, Adobe Photoshop was employed by carefully manipulating the selected images outlined in Figure 19 to produce print designs that meet contemporary trends (Figure 20 and Figure 21).

\subsection{Production of Prototypes (Simulation of the Design)}

These designs developed were simulated by simply superimposing the designs into an existing image using Adobe Photoshop (Figure 22) to see the outcome of the products. The 3D image was rendered onto a silhouette before arranging on a canvas of the document window.

\section{Discussion of the Results}

Using the Aesthetico-action research cycle in the studio-based methodology, elements were identified through observation for the execution of the project which included the Effutu emblem i.e. deer and stool, the arrow and the horn of Gologo. It was also identified in the study that; colours were of immense significance during the celebration of the Aboakyir festival and Gologo festivals. 


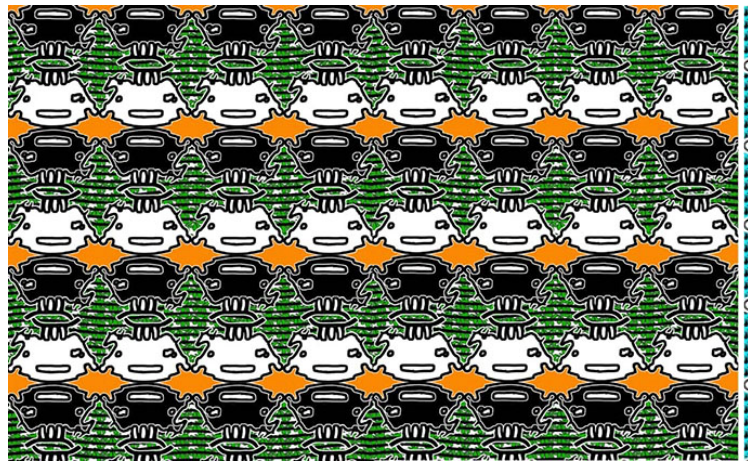

(a)

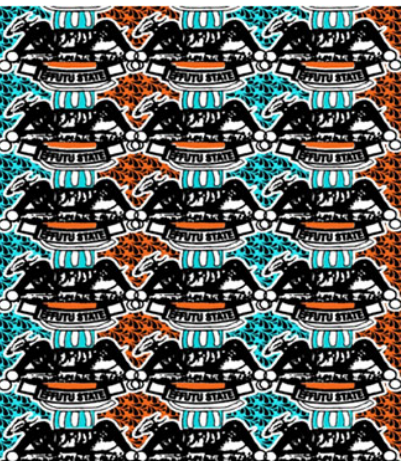

(b)

Figure 20. (a, b) Print designs from the Effutu emblem (Source: Studio Work, 2019).

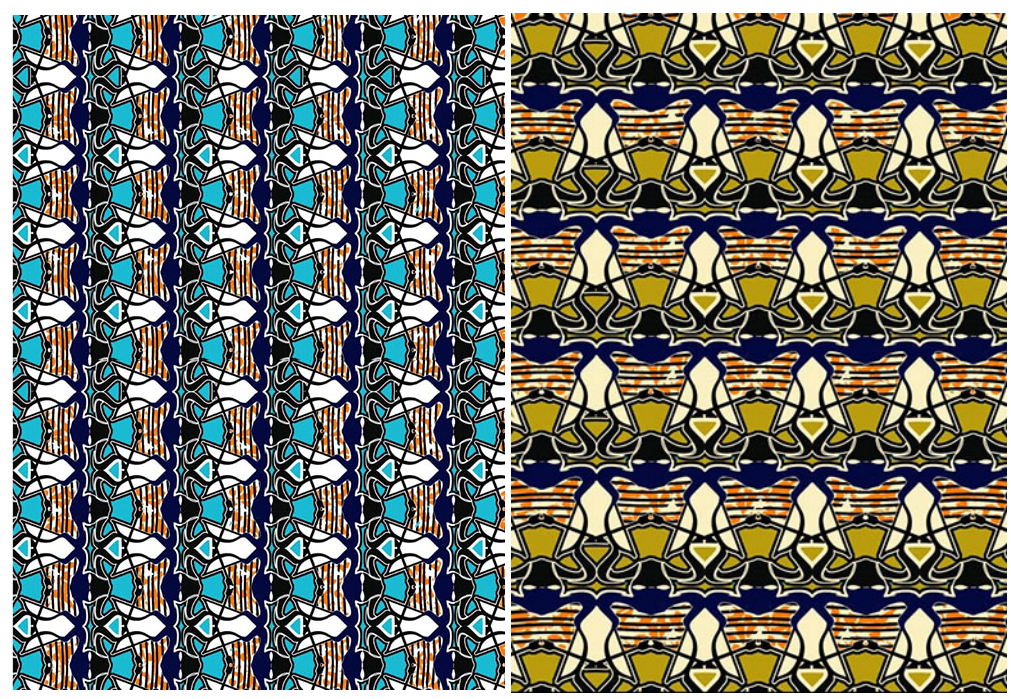

Figure 21. print design from horns and bows (Source: Studio Work, 2019).

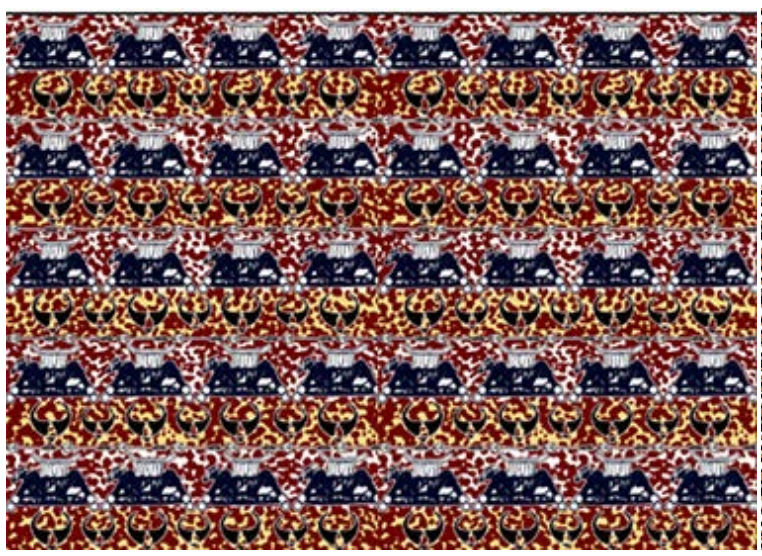

(a)

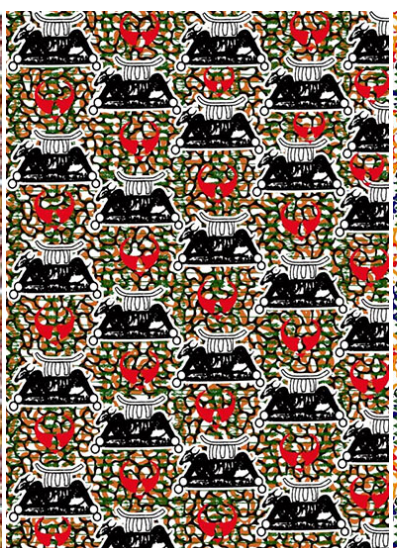

(b)

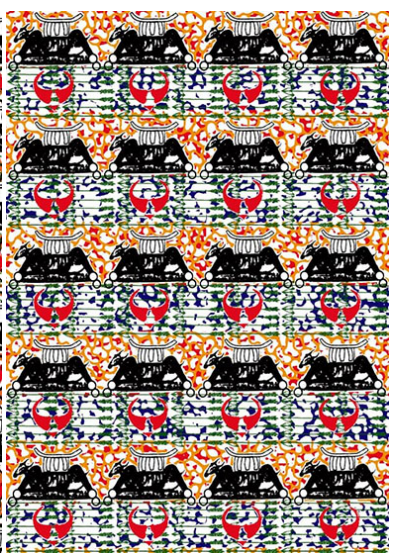

(c)

Figure 22. (a-c) Unity cloth.

Primary and secondary data for the study also revealed that; the dynamism in the cultures was vast but unexplored as inspiration for the creation of products. This created the need to explore the possibility of designing contemporary print 
and products from two festivals (Aboakyir and Gologo) using Adobe Photoshop in the design process. These elements were carefully arranged in an all-over pattern with textures into the cloth using Adobe Photoshop software as can be seen in Figure 20(a) and Figure 20(b); made from Effutu emblem (deer and stool), Figure 21(a) and Figure 21(b) from the arrow and the horn. Finally, by employing the concept of unity, elements from the Gologo festival (horns and bows) and Aboakyir festival (effutu emblem) were arranged in a design (Unity Cloth) with black, yellow, orange and white colour schemes as shown in Figure 22.

As established in the literature, [17] orate that, horns and bows are traditionally used for protection and for fighting. Protection is invaluable. The cloth designs created had simple motif arrangement and textures that would attract most of the youth in the catchment area and tourists.

Colour plays a crucial role in visual communication instantly stimulating our senses and elicits an emotional response. It has shaped human lives through history and beliefs of different cultures through the ages [18]. As humans, we prefer one or a maximum of two-three colours depending on where to use them while selecting garments or interior design.

Colour according to [19] is the fundamental building block of visual symbols. The symbolism of the colour in different cultures tends to have the common identification of colour names through cultural exchange. Colour, therefore, plays a very vital role in Aboakyir and Gologo festivals. From observation, colours commonly used during the celebration of these two festivals were blue, green, red, and yellow, orange, black, and white. The use of red and yellow during Aboakyir was often to distinguish between the two "Asafo" groups who hunted for the deer needed for the festival [20]. The colours used in these festivals had symbolic and specific meanings similar to Adinkra symbols and Kente Cloth Weave Patterns [21]. The colours used for the cloth designs and their meanings are as follows;

Blue represents peace, love, harmony and togetherness; maturity, spiritual energy, mourning, and passing rites. Green on the other hand signifies growth, harvest, and vegetation, spiritual growth, renewal, breaking of shackles, freedom from bondage, colour of fertility, and in the Christian context, it represents bountifulness, hope, and the victory of life over death. Yellow denotes prosperity, royalty, richness, fertility, a symbol of light, and purity. It speaks of youth, happiness, the harvest, hospitality, love, and benevolence.

Red shows good luck, celebration, action, fire, charity, spiritual awakening. It also glorifies the sun and the joy of life and love. The Christian symbolism denotes the Holy Spirit and the colour of Pentecost. Black represents the absolute, power, constancy, eternity or the womb, death, fear, and ignorance. White represents pureness, victory virtue cleansing rites, and festivals. Lastly, orange symbolises endurance and strength.

The designs produced, therefore, were unique, adorable and symbolic since it contained the elements used in the celebration of the festivals with the youth in 
focus as echoed by [21] that, during the festival, the main players wore costumes bearing the element of the area whereas the community members and tourist wore any type of garment. Festivals are occasions where various artefacts and cultures are exhibited [22]. Therefore, the simulated paraphernalia (Figure 23) will have a great impact on the celebration of the two festivals. The study brought to the fore, the hidden stories of some elements associated with the Aboakyir and Gologo festival celebration, which has now become the source of inspiration for textile design.

\section{Conclusions and Recommendation}

Culture is the backbone of vibrant societies and encapsulates their ideologies, philosophies, history, and facet of livelihood. Ghanaians, through their material culture, display interesting designs on artefacts and fabrics which are vibrant, communicate their beliefs, and display their ingenuity. Inspirations for these products, however, were centered on the Ashanti tribe with the overuse of Adinkra symbols and proverbial sayings. Studies revealed that other researchers have created equally interesting and culturally themed products using inspiration for the Ewe tribe, the Northern tribe among others.

The country, with 16 regions and over 100 ethnic groups, has diversified cultures that could be explored and created the need for the researchers to study and develop print designs inspired by elements of two festivals (Aboakyir and Gologo). Festivals are cultural activities that bring people from all walks of life together and allow the citizenry to showcase their cultural artefacts peculiar to their ethnic groups. This studio-based practice employed the Aesthetic-action research cycle in creatively coming out with the design with the aid of Adobe Photoshop. The final designs were simulated on images like an umbrella, keyrings, bags, etc. to visualize the outcome. The novelty in the research was the use of elements from the Aboakyir and Gologo festivals as inspiration to create individual

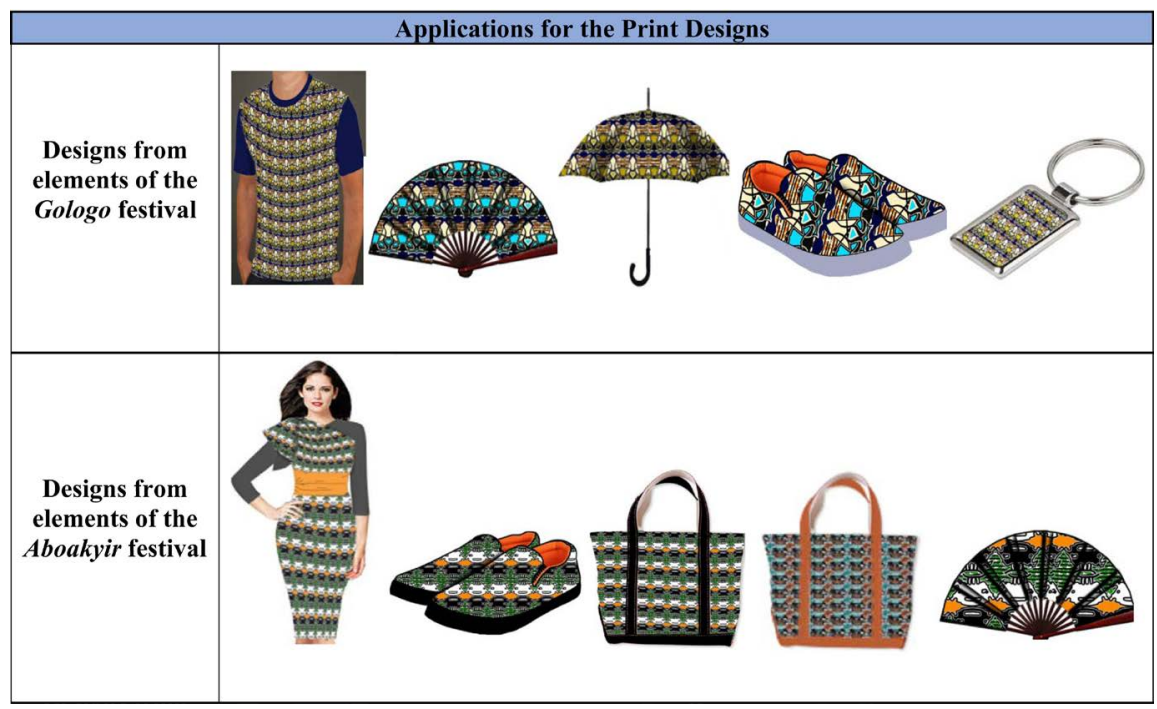

Figure 23. Simulation of designs (Source: Studio Work, 2019). 
and combined designs that were simulated on images that could be used as articles.

As stated earlier, the inspiration for print designs was only from the Ashanti tribe and though some researchers had tried to explore symbols, provers, and elements from other tribes, there has not been a study that pertains to that of Aboakyir and Gologo. This research has further simulated the prints on images to visualize the outcome of the products which is new in Ghana. In this part of the world, when designs are made; they are translated into products without simulation. The production of artefacts especially in the form of paraphernalia will help the citizenry and tourists acquire artefacts depicting the various elements used during festivals.

Apart from depicting the ethnic groups, it will further serve as a bridge between the traditional celebration and contemporary celebration telling history about the natives and their way of life. Some of the visual arts involved in the celebration were usually discarded after the festivals, but when they are in the form or paraphernalia, they will easily be reused daily. The possibility of this design practice proved that traditional elements from festivals can be employed in a design process to produce interesting prints that aim at promoting the cultural heritage and values in contemporary. Considering this, the planning committees of these festivals are advised to include photo exhibitions and documentary as part of the activities during the festivals.

It is further recommended that; the National Commission for Culture and Tourism should encourage designers to create artefacts using cultural elements which will serve as additional revenue for the tourist sites. It is recommended that the Traditional Council, have a museum or gallery for keeping the artworks used in their festivals for archival purposes.

\section{Conflicts of Interest}

The authors declare no conflicts of interest regarding the publication of this paper.

\section{References}

[1] Vigbedor, D., Gbadegbe, R.S., Adja-Koadade, M. and Agra, F. (2016) Ewe Proverbs-A Source of Imagery for Textile Designs. Arts and Design Studies, 46, 42-66.

[2] Seidu, K.R. (2019) Exploring Liquefy Tools of CAD Software in Reinventing Cultural Elements for Innovative Textile Designs. Kwame Nkrumah University of Science and Technology, Kumasi.

[3] Ayesu, M.S. (2015) Empirical Study of Akuapem Odwira Festival and Traditional State Symbols: A Means for Design and Production of Textile Regalia for Akuapem Paramount Chief. Kwame Nkrumah University of Science and Technology, Kumasi.

[4] Asare, K.D., Howard, K.E. and Ibrahim, F.A. (2016) The Aesthetic and Philosophical Values of Asante Linguist Staff Symbols in Textile Design. International Journal of Innovative Research \& Development, 5, 225-237.

[5] Safo-Ankama, K. (2019) Adaptation of Indigenous Structural Textile Designs for Textile Prints: The Case of Selected Fugu Fabric Designs. Journal of African Arts \& Culture, 3, 1-23. 
[6] Clement, F.A. (2011) A Seat Inspired by a Traditional Symbol from Ghana. Akershus University College, Lillestrøm.

[7] Oduro-Awisi, K.A. (2013) Chieftaincy Disputes in Akuapem Traditional Area: A Search for Solution. Faculty of Social Sciences Department of Religious Studies, Kwame Nkrumah University of Science and Technology, Kumasi.

[8] Hall, M. (2000) The Future of Tourism: A Personal Speculation. Tourism Recreation Research, 25, 85-95. https://doi.org/10.1080/02508281.2000.11014902

[9] Akintan, O.A. (2013) Traditional Religious Festivals and Modernity: A Case Study of Female-Oriented Cults Annual Festivals in Ijebuland of South Western Nigeria. International Journal of Social Science and Education, 3, 1035-1046.

[10] Impraim-swanzy, E. (2015) Artistic Elements in the Festivals of the Effutus-Ghana, Faculty of Art, College of Art and Built Environment. Department of General Art Studies, Kwame Nkrumah University of Science and Technology, Kumasi.

[11] Okpu, O. (2015) Costume and Body Adornment in Dance: A Case Study of Abame Festival in Igbide: Isoko Local Government Area of Delta State, Nigeria. International Journal of Arts, 5, 21-31.

[12] Eze, C. and Akas, N. (2015) Costume and Make up, as a Tool for Cultural Interpretation: A Study of Egba Festival of the Kokori, Isoko Local Government Area of Delta State. Journal of Art and Design Studies, 36, 22-34.

[13] Filippos, F., Ivonni, H. and Christos, K. (1995) Dance and Costume. From the Tradition Performance. Folklore, 23, 107-114.

http://www.folklore.ee/folklore/vol23/costume.pdf http://doi.org/10.7592/FEJF2003.23.costume

[14] Arku J. (2013) Fugu-The Tradition Goes on. http://www.graphic.com.gh/features/features/fugu-the-tradition-goes-on.html

[15] Gbadegbe, R.S and Mensah, C. (2013) The Role of Art Forms in the Celebration of Festivals: A Case Study of Asogli Yam Festival. Volta Region, Ghana. Arts and Design Studies, 12, 35-41. http://www.iiste.org

[16] Adjei, A.D., Sarfo, F. and Adongo, G. (2016) Analysis of the Art Forms Used as a Costume in the Gologo Festival of the People of Tongo in the Upper East Region of Ghana. Arts and Design Studies, 41, 28-34.

[17] Adjei, A.D. and Sarfo, F. (2016) Significance of the Costume Used for the Dia War Dance by the Frafra People of the Upper East Region of Ghana. Journal of Culture, Society and Development, 24, 44-50.

[18] Yu, H.-C. (2014) A Cross-Cultural Analysis of Symbolic Meanings of Colour. Chang Gung Journal of Humanities and Social Sciences, 7, 49-74.

[19] Lamara, K. (2017) Psychological and Physiological Effects of Colour in Cross-Cultural and Business Communication. Grigol Robakidze University, Georgia.

[20] Takyi, E.H. (2015) A Comparative Study of the Concept of Atonement in the Aboakyir Festival of the Effutu Tribe in Ghana and the Yom Kippur Festival of the Old Testament: Implications for Adventist Mission among the Effutu. Seventh-day Adventist Theological Seminary, Berrien Springs.

[21] Kodzo, L. (2017) Kente Cloth: Everything You Need to Know about Kente. KENTECLOTH.NET, Virginia.

[22] Nortey, S. (2009) The Homowo Festival in Accra: Its Artistic Cultural Aspects. Kwame Nkrumah University of Science and Technology, Kumasi. 